This item was submitted to Loughborough's Research Repository by the author.

Items in Figshare are protected by copyright, with all rights reserved, unless otherwise indicated.

\title{
Wage-setting institutions and R\&D collaboration networks
}

\section{PLEASE CITE THE PUBLISHED VERSION}

http://dx.doi.org/10.1111/1467-8454.12009

\section{PUBLISHER}

John Wiley \& Sons (@ University of Adelaide and Flinders University and Wiley Publishing Asia Pty Ltd.)

\section{VERSION}

AM (Accepted Manuscript)

\section{PUBLISHER STATEMENT}

This work is made available according to the conditions of the Creative Commons Attribution-NonCommercialNoDerivatives 4.0 International (CC BY-NC-ND 4.0) licence. Full details of this licence are available at: https://creativecommons.org/licenses/by-nc-nd/4.0/

\section{LICENCE}

CC BY-NC-ND 4.0

\section{REPOSITORY RECORD}

Ferrett, Benjamin E., and Vasileios Zikos. 2019. "Wage-setting Institutions and R\&D Collaboration Networks". figshare. https://hdl.handle.net/2134/23371. 


\title{
Wage-Setting Institutions and R\&D Collaboration Networks*
}

\author{
Ben Ferrett ${ }^{\dagger}$ and Vasileios Zikos ${ }^{\ddagger}$
}

29 November 2012

\begin{abstract}
We analyse how union structures that differ in the degree of wage-setting centralisation affect the pattern of R\&D network formation. Within the context of a three-firm industry, a central union that sets a uniform wage is shown to induce a partial R\&D network that includes two firms but excludes the third. In contrast, we find that, under less centralised union structures, firms have incentives to form R\&D networks with a larger number of alliances. This result is consistent with the stylised facts for industrialised countries: recent decades have seen an upsurge in $\mathrm{R} \& \mathrm{D}$ alliances along with labour market deregulation towards more flexible wage-setting institutions.
\end{abstract}

Keywords: Networks, R\&D collaboration, unionisation structures.

JEL Classification: L13, J51, D85.

\footnotetext{
*We would like to thank an anonymous referee for valuable comments.

${ }^{\dagger}$ Corresponding author: School of Business and Economics, Loughborough University, Loughborough, LE11 3TU, United Kingdom. Email: b.e.ferrett@lboro.ac.uk.

${ }^{\ddagger}$ School of Economics, University of Surrey, Guildford, Surrey, GU2 7XH, United Kingdom, Email: V.Zikos@surrey.ac.uk; and Research Institute for Policy Evaluation and Design, University of the Thai Chamber of Commerce, 126/1 Vibhavadee-Rangsit Road, Dindaeng, Bangkok, 10400, Thailand, Email: V.Zikos@riped.utcc.ac.th.
} 


\section{Introduction}

An important dimension of wage-setting negotiations is the level where collective contracts are formally set. Between the 1970s and the 1990s it appears that no country moved towards a more centralised system, and most countries progressively adopted wage-setting institutions characterised by a lower degree of centralisation (OECD, 2004). For instance, in the US, Canada and Japan wage negotiations are decentralised at the firm-level. More recently, the UK and New Zealand joined this group of countries. Furthermore, countries such as Germany that traditionally negotiated over wages at a relatively high degree of centralisation adopted "intermediate" systems, which permit wage adjustments at the firm level while negotiations remain under the auspices of an industry union (Haucap and Wey, 2004).

Since the mid-1970s we have also witnessed an upsurge in the extent of R\&D collaborations between firms. This has led to the so-called "age of alliance capitalism" (Narula and Duysters, 2004), where hi-tech firms collaborate in a variety of ways to share know-how and enhance technological capabilities. Moreover, empirical evidence suggests that the importance of nonequity types of collaboration, such as $R \& D$ networks, has increased strongly relative to more traditional, equity-based alliances, such as research joint ventures. For example, in the cases of pharmaceuticals and biotechnology, Roijakkers and Hagedoorn (2006) show that non-equity forms of collaborative activity grew steadily in relative importance during the 1980s and 1990s, accounting recently for more than $90 \%$ of the total number of R\&D collaborations.

Motivated by the aforementioned stylised facts - labour market deregulation and the spread of R\&D networks between firms - the following question arises: Might recent trends towards introducing more flexibility into wage-setting have increased the profitability of R\&D collaborations between firms, and hence contributed to the spread of R\&D networks? In this paper we use a model of endogenous network formation to address this question.

Our central results emerge from comparing firms' network formation decisions under three 
distinct wage-setting regimes - "centralisation", "coordination" and "decentralisation". ${ }^{1}$ Under centralisation, a single industry-wide union sets a uniform wage for all workers; whereas, under coordination, it sets discriminatory wages between firms. In contrast, under decentralisation, there are independent firm-level unions. Thus, centralisation and decentralisation can be seen as polar cases, whereas coordination can be seen as intermediate. In the context of a threefirm model with endogenous $\mathrm{R} \& \mathrm{D}$ investments, we show that the transition from centralised to decentralised wage-setting causes the number of REBD links between firms to rise. This is our central result, and it is consistent with the stylised facts documented above.

The paper closest in spirit to ours is Mauleon et al. (2008), who study R\&D network formation in a decentralised regime of firm-level unions. In that context, the authors demonstrate the emergence of the complete R\&D network, where each firm maintains links with both its rivals. Imagine that two firms are linked and the third is isolated - that is, the R\&D network has an insider/outsider or partial pattern. In that case, the linked firms will pay higher wages than the isolated firm. This is because unions set wages after firms have made their R\&D collaboration and investment decisions. ${ }^{2}$ Linked firms thus face a hold-up problem, whereby higher levels of R\&D investment/collaboration induce higher wages. However, this wage premium means that the linked firms suffer in product-market competition. By bringing the outsider into the R\&D network, which increases the outsider's access to R\&D and thus its wage, the two insiders are able to reduce this "business stealing" effect. Therefore, the complete network emerges endogenously under decentralisation.

Our results for centralised wage-setting, which represents the other extreme to decentralisation, are new. With a uniform wage, the isolated firm that faces two linked rivals is unable to benefit from a lower wage. Thus, the business stealing effect is absent, and the linked firms have no incentive to expand their partial R\&D network in order to raise their rival's costs.

\footnotetext{
${ }^{1}$ Our terminology here follows Haucap and Wey (2004).

${ }^{2}$ This sequencing of moves reflects the fact that wages are relatively easy to alter.
} 
Therefore, under centralisation, only one $R \& D$ link is established within the industry, and an insider/outsider formation results.

Consider next the intermediate case of coordinated wage-setting, where an industry-wide union sets firm-specific wages. In that case, we show that the complete R\&D network arises in equilibrium, but only if within-network R\&D spillovers are sufficiently small. The basic intuition for the emergence of the complete network is similar to the decentralised case: when wages can differ across firms, linked firms pay a wage 'penalty' due to their higher cost efficiency. However, the industry-wide union internalises the business stealing effect created by the wage cut at the isolated firm - in a way that does not occur when three independent unions compete under decentralisation. Therefore, under coordination, the complete network emerges endogenously, but it is less attractive than under decentralisation.

Our paper contributes to three main strands of the literature. First, it contributes to the rapidly expanding literature on $R \& D$ networks. The seminal paper by Goyal and MoragaGonzález (2001) and several extensions (see e.g. Deroian and Gannon, 2006; Zikos, 2010; Zirulia, 2012) offer models of horizontal R\&D networks. This line of research has generally ignored the role of input markets on network formation, though a notable exception is Mauleon et al., as explained above. ${ }^{3}$ Importantly, however, our results on the effects of labour market deregulation contrast sharply with those arising in Mauleon et al. (2008), where the focus is on the distribution of bargaining power rather than, as here, changes in labour market structure. Under the assumption that wage bargaining is decentralised to firm-level unions, Mauleon et al. show that more inter-firm R\&D collaboration links tend to emerge when bargaining power rests with the unions rather than with the firms. However, the finding that the intensity of R\&D collaborations should be positively correlated with union bargaining power is empirically troubling because the stylised facts surveyed earlier suggest the opposite - across industrialised

\footnotetext{
${ }^{3}$ Together with Mauleon et al. (2008), our paper can be thought of as an attempt to extend the R\&D network literature vertically by examining the effects of different unionisation structures on firms' incentives to establish collaborative R\&D links.
} 
countries, inter-firm R\&D collaborations have become hugely more prevalent as labour markets have been deregulated and unions weakened. ${ }^{4}$

Second, our paper contributes to the literature on unionisation and innovation. In contrast to our model, most existing studies of trade unions and R\&D concentrate on how the presence of unions affects the $\mathrm{R} \& \mathrm{D}$ incentives of individual (isolated) firms. ${ }^{5}$ A generic finding is that decentralised unions discourage R\&D due to the hold-up problem. However, offsetting that, we show that decentralised unions promote the formation of $R \& D$ links and the complete $R \& D$ network - thus increasing the extent to which $R \& D$ results are effectively applied to production. Analysing this additional avenue - network formation - through which unions can affect R\&D performance is a contribution of this paper.

In the same line of research, the analysis by Mukherjee and Pennings (2011) is closest to our own. The authors develop a model to study the impact of unionisation structure on firms' incentives for technology licensing and innovation. Interestingly, the main mechanism that determines licensing decisions in their paper also determines firms' incentives to form network links in our paper. In particular, the intensity of the hold-up problem faced by linked firms is reduced by competing trade unions under decentralisation, while it is reduced by the uniformity rule under centralisation (Mukherjee and Pennings, 2011). ${ }^{6}$ As it turns out, competition between decentralised unions - in line with Mukherjee and Pennings (2011) - implies a more effective mechanism in mitigating the hold-up problem, and thus, it encourages the creation of more links between firms.

Finally, our analysis is related to the literature that analyses R\&D collaborations within research joint ventures (RJVs). ${ }^{7}$ Building on the influential paper by d' Aspremont and Jacquemin

\footnotetext{
${ }^{4}$ We should note, however, that Mauleon et al. present supportive data for their results from the Canadian biotech industry.

${ }^{5}$ See, for example, Grout (1984), Tauman and Weiss (1987), Ulph and Ulph (1994, 2001), Calabuig and González-Maestre (2002), Haucap and Wey (2004), and Menezes-Filho et al. (1998) for empirical evidence.

${ }^{6}$ The case of a coordinated regime can be seen as an intermediate situation.

${ }^{7}$ See, for example, d' Aspremont and Jacquemin (1988); Suzumura (1992); Poyago-Theotoky (1995); Kamien, Muller and Zang (1992); Amir (2000).
} 
(1988), Manasakis and Petrakis (2009) show that the incentives to form RJVs under decentralised vis-à-vis centralised unions are sensitive to the extent of public spillovers. There are, however, two important differences between this line of work and our paper. First, it is typically assumed that all firms within the industry participate in the RJV - so questions about the extent of the network cannot be addressed. Second, it is assumed that R\&D investments are determined co-operatively. ${ }^{8}$ In contrast, an R\&D network is a non-equity form of collaboration, as explained above. Thus, firms retain their own R\&D labs and agree to pool their R\&D results by forming collaborative links.

The remainder of the paper is organised as follows. The next section presents our model and our equilibrium concepts. Section 3 analyses the cases of decentralised and centralised wage-setting, and considers the impact of labour market deregulation. Section 4 analyses the intermediate regime of coordinated wage-setting. Section 5 discusses various aspects of our results, particularly their relation to the wider literature and their normative properties. Finally, section 6 concludes.

\section{Model}

Sequence of moves. Three firms are competing to supply the market for a homogeneous good. Following Mauleon et al. (2008), MSMV hereafter, our game has four stages. In stage one, the firms form collaboration links between themselves for the sharing of $\mathrm{R} \& \mathrm{D}$ results. In stage two, firms carry out their process $\mathrm{R} \& \mathrm{D}$ investments simultaneously and independently. In stage three, wage rates are determined (they may be firm-specific or common). Finally, in stage four, the firms compete à la Cournot on the product market, subject to the linear inverse demand function $p=a-\sum_{1}^{3} q_{i} \cdot{ }^{9}$ This sequencing can be justified by considering the relative

\footnotetext{
${ }^{8}$ An exception to the norm of R\&D co-operation, which is closer in spirit to our approach, is the "RJV competition" case of Kamien et al. (1992).

${ }^{9}$ Our qualitative results survive if we assume instead Bertrand competition with differentiated goods. Computations available on request.
} 
degrees of commitment in each decision - for example, wages are easier to change than R\&D investments.

Marginal costs, and R\&D investments and outputs. Marginal costs are constant, and they can be reduced by both process R\&D investment and the formation of collaboration links to pool R\&D outputs with other firms. We assume that the production of one unit of the final good requires one unit of labour (paid wage $w_{i}$ ), and that $\mathrm{R} \& \mathrm{D}$ works to reduce the non-labour part of marginal cost (initially equal to $\bar{c}$ ). ${ }^{10}$ Firm $i$ 's R\&D output is $x_{i}$, and the associated R\&D investment cost is $x_{i}^{2}$.

Our assumption that firms choose their R\&D investments independently captures a lack of trust between network partners. It reflects the fact that it is not possible to write complete contracts on $R \& D$ behaviour. This is a natural assumption because $R \& D$ investments are often hard to observe (e.g. when a multi-product firm maintains a single research lab) and R\&D outputs are often unknowable ex ante.

Collaboration networks and $\mathbf{R} \& \mathbf{D}$ spillovers. Network formation affects marginal costs because it allows access to other firms' $R \& D$ outputs. Like the existing literature on $R \& D$ networks (e.g. Goyal and Moraga-González, 2001), we assume that the formation of R\&D links between firms is costless.

In a triopoly, four distinct $R \& D$ networks are possible - see Figure 1.

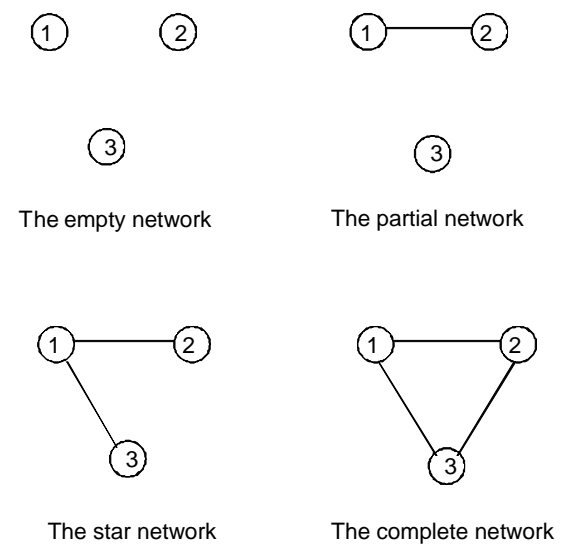

\footnotetext{
${ }^{10}$ This is consistent with $\mathrm{R} \& \mathrm{D}$ reducing the capital/labour ratio within a Leontief production function. Note that, depending on the system of wage-setting, the wage $w_{i}$ may be firm-specific or common.
} 
In the empty network, there are no links between firms, and each firm's marginal cost is given by

$$
c_{i}=\bar{c}+w_{i}-x_{i}, \text { where } i \in\{1,2,3\}
$$

The other three networks all contain links between firms. These collaboration links give firms access to the R\&D outputs of their partner/s. In the partial network, a single link exists - and we assume, w.l.o.g., that this is between firms 1 and 2, the insiders. Marginal costs are thus given by

$$
\begin{array}{cl}
\text { Insiders: } & c_{i}=\bar{c}+w_{i}-x_{i}-\beta x_{j}, \text { where } i, j \in\{1,2\} \text { and } i \neq j \\
\text { Outsider: } & c_{3}=\bar{c}+w_{3}-x_{3}, \text { as in the empty network }
\end{array}
$$

Thus, each insider enjoys access to a proportion $\beta \in[0,1]$ of its partner's $\mathrm{R} \& \mathrm{D}$ output.

In the star network, there are two links, creating a hub-and-spoke pattern. W.l.o.g., we assume that firm 1 is the hub. Firms 2 and 3, the spokes, receive direct access to firm 1's R\&D output, and they can also access - indirectly, via the hub - the R\&D output of the other spoke. To capture this relatively large distance within the network between the spokes, we assume that each spoke only receives a proportion $\frac{\beta}{2}$ of the other spoke's R\&D output. Thus,

$$
\begin{aligned}
\text { Hub: } & c_{1}=\bar{c}+w_{1}-x_{1}-\beta\left(x_{2}+x_{3}\right) \\
\text { Spokes: } & c_{i}=\bar{c}+w_{i}-x_{i}-\beta x_{1}-\frac{\beta}{2} x_{j}, \text { where } i, j \in\{2,3\} \text { and } i \neq j
\end{aligned}
$$

Finally, in the complete network, each firm maintains two links, and marginal costs are given by

$$
c_{i}=\bar{c}+w_{i}-x_{i}-\beta\left(x_{j}+x_{k}\right), \text { where } i, j, k \in\{1,2,3\} \text { and } i \neq j \neq k
$$


Wage-setting. Wages are set in stage three, and we consider three distinct wage-setting regimes (following Haucap and Wey, 2004). We assume that wages are set unilaterally by the respective labour union/s - the "monopoly union" model - and we normalise the reservation wage to $0 .{ }^{11}$

Under decentralisation, there are three independent firm-specific unions, each of which sets $w_{i}$ to maximise its firm's wage bill, $w_{i} q_{i}$ where $i \in\{1,2,3\}$. (Recall that employment $=$ output by assumption.) Alternatively, there might be a single, industry-wide union, and the issue then is whether that single union sets a uniform wage for all workers in the industry, which we term centralisation, or firm-specific wages, which we term coordination. Thus, under centralised wagesetting, the union sets $w$ to maximise $w \sum_{1}^{3} q_{i}$ where $i \in\{1,2,3\}$; whereas under coordinated wage-setting, it sets $w_{i}$ to maximise $\sum_{1}^{3} w_{i} q_{i}$.

A key assumption is that workers are not mobile across unions - thus, wage differences across firms can be sustained. (For example, workers may have undertaken firm-specific training, which increases their switching costs and creates "lock-in".) In terms of the degree of "centralisation" in wage-setting, we see the decentralisation and centralisation regimes as extremes, with coordinated wage-setting as an intermediate case.

We take the wage-setting regime as exogenous. Labour market institutions are typically economy-wide and often determined by national legislation, so it is reasonable to assume that the wage-setting regime is exogenous to any particular industry.

\subsection{Equilibrium concepts}

We solve the game backwards from stage 4 (Cournot competition) to stage 2 (R\&D investments) inclusive. Thus, network-formation decisions in stage 1 take into account the subsequent effects on R\&D levels, wages and outputs - and equilibrium solutions for these variables are given in

\footnotetext{
${ }^{11}$ We adopt the monopoly union model for simplicity. We expect our qualitative results to survive under the more general right-to-manage bargaining model - as long as the union/s possess some bargaining power to drive wages above the exogenous reservation level.
} 
the Appendix.

We use two well-established equilibrium concepts for network formation in stage 1. Following Jackson and Wolinsky (1996), we say that a network is pairwise stable if no firm benefits from unilaterally severing one of its R\&D links and no two firms benefit from adding a new link between them. If we think of the four possible network architectures as arranged in the sequence \{empty, partial, star, complete\}, then pairwise stability refers to a deviation to a neighbouring architecture.

To derive our main results, we use the strong stability notion of Jackson and van den Nouweland (2005), which is a refinement of pairwise stability. ${ }^{12}$ A strongly stable network is one that is stable against changes in $\mathrm{R} \& \mathrm{D}$ links by any coalition of firms within the industry - because at least one firm in the coalition would lose from the proposed group deviation. Thus, in terms of the four-network sequence above, strong stability considers deviations to any alternative architecture.

It is important to note that both of these network equilibrium concepts rule out side payments between firms. If such side payments were permitted and binding contracts could be written, then we would expect the R\&D network to emerge that maximises industry profits. In contrast, industry profits provide no guide to either pairwise or strong stability. ${ }^{13}$

Notation for equilibrium profits. We adopt the following notation for equilibrium profits, which exploits the symmetries across firms:

$\Pi^{E}$ denotes a firm's profits in the empty network;

$\Pi^{I}$ denotes the profits of an insider (linked) firm in the partial network;

$\Pi^{O}$ denotes the profits of outsider (isolated) firm in the partial network;

$\Pi^{H}$ denotes the hub firm's profits in the star network;

\footnotetext{
${ }^{12}$ Thus, only pairwise stable networks can be strongly stable.

${ }^{13}$ For all three wage-setting regimes, the complete network maximises industry profits for almost all $\beta$. However, the complete network is not always strongly stable, and under centralisation the alternative, partial network is the unique strongly stable network.
} 
$\Pi^{S}$ denotes a spoke firm's profits in the star network; and

$\Pi^{C}$ denotes a firm's profits in the complete network.

\section{Equilibrium network structures}

\subsection{Decentralised wage-setting}

The institutional regime of decentralised negotiations is prevalent in Canada, Japan, Korea, and the United States, which traditionally engaged in negotiations at the firm-level. More recently, the United Kingdom, New Zealand and some eastern European countries have also adopted the same form of wage negotiations.

Decentralisation is formally identical to the unions-set-wages case in MSMV, so we merely report the key results briefly.

Proposition 1 (MSMV, 2008): Under decentralised wage-setting, the complete network is the unique pairwise and strongly stable network for all levels of within-network RED spillovers.

For all levels of spillovers within a network $\beta$, the following ranking of firms' profits holds: ${ }^{14}$

$$
\Pi^{H}>\Pi^{C}>\Pi^{I}, \Pi^{S}>\Pi^{E}>\Pi^{O}
$$

Note that the first two terms are separated by a comma, not $>$. Specifically, $\Pi^{I}>\Pi^{S}$ if and only if $\beta>0.12$; otherwise, $\Pi^{S}>\Pi^{I}$. This ranking implies that, in the empty, partial and star networks, two unconnected firms would both gain by forming a new link between themselves, ${ }^{15}$ so the complete network is the only pairwise stable network and thus the only candidate for strong stability. Turning to strong stability, from the complete network, the three firms will not

\footnotetext{
${ }^{14}$ Plots of equilibrium firm-level profits are available from the authors on request.

${ }^{15}$ Proof: $\Pi^{I}>\Pi^{E}$ so the empty network is not pairwise stable; $\Pi^{H}>\Pi^{I}$ and $\Pi^{S}>\Pi^{O}$ so the partial network is not pairwise stable; and $\Pi^{C}>\Pi^{S}$ so the star network is not pairwise stable. Of course, $\Pi^{C}>\Pi^{S}$ also implies that the complete network is pairwise stable - no firm will unilaterally delete a link to become a spoke.
} 
deviate to the empty network (because $\Pi^{C}>\Pi^{E}$ ), and pairwise stability rules out a deviation to the star. Finally, no two firms will form a coalition to deviate from the complete to the partial network - by severing their links with the third firm - because $\Pi^{C}>\Pi^{I}$. Therefore, the complete network is strongly stable.

\subsection{Centralised wage-setting}

This characterisation of wage setting, where an industry-wide union sets a uniform wage, is consistent with existing practices in Norway, Finland, Ireland and Portugal (see OECD, 2004).

For all levels of spillovers within an $\mathrm{R} \& \mathrm{D}$ network $\beta$, the firms' profits are ranked as follows:

$$
\Pi^{I}, \Pi^{H}>\Pi^{C}>\Pi^{S}>\Pi^{E}>\Pi^{O}
$$

Note, importantly, that the ranking of $\Pi^{I}$ and $\Pi^{H}$ depends on $\beta$, and it will be important for our results below. Specifically, $\Pi^{I}>\Pi^{H}$ if and only if $\beta>\beta^{*} \approx 0.4895 .{ }^{16}$

Proposition 2: Assume centralised wage-setting. (i) The complete network is pairwise stable but not strongly stable. (ii) If within-network RED spillovers are sufficiently large, the partial network is both pairwise and strongly stable. (iii) Neither the empty nor the star network is ever pairwise stable.

Part (i) is proved as follows. Pairwise stability is implied by $\Pi^{C}>\Pi^{S}-$ a firm in the complete network will not unilaterally sever a link to become a spoke in the star; of course, this also implies that the star network is not itself pairwise stable, as part (iii) states. Although the three firms in the complete network will not jointly deviate to the empty network (because $\Pi^{C}>\Pi^{E}$ ), it is the case that (in contrast to decentralisation) two of the firms in the complete network will force a deviation to the partial network by severing their links with the third firm (because $\Pi^{I}>\Pi^{C}$ ). Thus, the complete network is no longer strongly stable.

\footnotetext{
${ }^{16}$ Thus $\Pi^{I}$ and $\Pi^{H}$ intersect only once on $\beta \in[0,1]$.
} 
By comparing (2) and (1), note that $\Pi^{I}>\Pi^{C}$ under centralisation but not under decentralisation - this is the key condition that undermines the strong stability of the complete network under centralisation. Intuitively, $\Pi^{I}>\Pi^{C}$ arises under centralisation because the uniform wage mitigates the hold-up problem faced by the insiders in the partial network, who enjoy substantially greater access to R\&D results than the isolated, outsider firm. However, under decentralisation, the hold-up problem leads the linked firms in the partial network to pay substantially higher wages than the isolated firm - hence $\Pi^{C}>\Pi^{I}$.

Part (ii) of Proposition 2 is proved as follows. Pairwise stability requires $\Pi^{I}>\Pi^{E}$, which holds and ensures that neither of the insiders will unilaterally break their link (this also, of course, implies that the empty network is not pairwise stable - part (iii) of Proposition 2). However, because $\Pi^{S}>\Pi^{O}$ (a spoke in the star network earns more than the outsider in the partial network), pairwise stability also requires $\Pi^{I}>\Pi^{H}$ to rule out a deviation to the star network - i.e. that the insiders in the partial network earn more than the hub in the star. In turn, $\Pi^{I}>\Pi^{H}$ holds for $\beta>\beta^{*} \approx 0.4895$ - i.e. sufficiently large within-network R\&D spillovers. It seems reasonable to suppose that this requirement will be satisfied because the degree of spillovers within a network is, to a significant extent, a choice variable for the firms involved.

The intuition behind the need for sufficiently large spillovers to ensure $\Pi^{I}>\Pi^{H}$ runs as follows. Both the insiders in the partial network and the hub in the star benefit from a rise in spillovers. However, the partial-network insiders benefit by more because they are competing against an unconnected, outsider firm - whereas all firms, hub and spokes, in the star network benefit from greater R\&D spillovers.

Finally, if the partial network is pairwise stable (which rules out deviations to empty/star), then it follows immediately that it is also strongly stable because $\Pi^{I}>\Pi^{C}-$ that is, the insiders in the partial network will not agree to a coalitional deviation to the complete network. 


\subsection{Centralisation versus Decentralisation}

The comparison of centralised and decentralised wage-setting (Propositions 1 and 2) gives us a key result:

Proposition 3: If within-network RESD spillovers are sufficiently large, then a transition from centralised to decentralised wage-setting causes the complete network to displace the partial network as the unique strongly stable network.

This result is consistent with the stylised facts, surveyed in the Introduction, that the growth of R\&D networks between firms has accompanied labour market deregulation. Moreover, the qualification in Proposition 3 on the size of spillovers is needed only to pin down the strongly stable network under centralised wage-setting (as the partial network). As Proposition 1 makes clear, we can be confident - even for small within-network R\&D spillovers, $\beta$ - that the introduction of decentralised wage-setting will provoke the formation of the complete network. Thus, labour labour deregulation that results in decentralised wage-setting would never be expected to lead to a fall in the number of $R \& D$ links between firms.

For any wage-setting regime, the ranking of firm profits is clearly central to the determination of the equilibrium R\&D network/s. Common to the profit rankings for both decentralisation and centralisation, (1) and (2), is

$$
\Pi^{H}>\Pi^{C}>\Pi^{S}>\Pi^{E}>\Pi^{O}
$$

The variable is the position in the ranking of $\Pi^{I}$.

The "common" ranking in (3) above makes intuitive sense. The outsider in the partial network performs worse than any of the firms in the empty network $\left(\Pi^{E}>\Pi^{O}\right)$ because it is in a weaker position vis-à-vis its competitors (who are linked), whereas all firms in the empty 
network are identical. ${ }^{17}$ Likewise, compared to a firm in the complete network, the hub firm in the star performs better $\left(\Pi^{H}>\Pi^{C}\right)$ and the spoke firms worse $\left(\Pi^{C}>\Pi^{S}\right)$ - that is, deleting a link from the complete network benefits the hub-designate but harms the spokes-designate.

In relative terms, $\Pi^{I}$ is higher under centralisation than under decentralisation. As explained above, this can be understood by considering the hold-up problem faced by the insider firms in the partial network. Under centralisation, there is one industry-wide union and a uniform wage - therefore, there is relatively little hold-up of the linked firms in the partial network. In contrast, under decentralisation, there are three independent unions, so the insiders in the partial network face substantially higher wages than the outsider.

\section{Coordinated wage-setting}

Centralisation and decentralisation may be regarded as the two extreme forms of wage-setting regime in the presence of trade unions. Therefore, partly as a robustness check, we consider an intermediate regime in this section - "coordination". ${ }^{18}$ Under coordination, a single industrywide union sets firm-specific wages.

We believe that coordinated wage-setting is a fair representation of some recent reforming trends in employment relations in continental Europe. For example, in Germany, the Netherlands and, to some extent, in Spain, wage negotiations include "opening" clauses, which, under certain circumstances, allow firms to negotiate with their workforce wages below the level collectively agreed at an industry level (see OECD, 2004). Moreover, coordination also appears to characterise the arbitration system in Australia where wage negotiations have progressively moved towards the level of the individual enterprise with a "safety net" at national level (see, again, OECD, 2004).

An alternative interpretation of coordinated wage-setting would be that firm-specific unions

\footnotetext{
${ }^{17}$ Adding a single link to the empty network benefits the insiders-designate but harms the outsider-designate.

${ }^{18}$ Our terminology again follows Haucap and Wey (2004).
} 
act collusively with a view to coordinating their wage claims.

For all levels of spillovers within an $\mathrm{R} \& \mathrm{D}$ network $\beta$, the firms' profits under coordination are ranked as follows:

$$
\Pi^{H}>\Pi^{C}, \Pi^{I}>\Pi^{S}>\Pi^{E}>\Pi^{O}
$$

Note that the ranking of $\Pi^{C}$ and $\Pi^{I}$ depends on $\beta$, and it will be important for our results below. Specifically, $\Pi^{C}>\Pi^{I}$ if and only if $\beta<\beta^{* *} \approx 0.7686$.

Proposition 4: Under co-ordinated wage-setting, the complete network is the unique pairwise stable network for all levels of within-network REBD spillovers, and it is strongly stable if spillovers are sufficiently small.

We first prove that the complete network is the unique pairwise stable network (and thus the only candidate for strong stability). To rule out pairwise stability for the other networks, observe that $\Pi^{I}>\Pi^{E}$ (so the empty network is not pairwise stable); $\Pi^{H}>\Pi^{I}$ and $\Pi^{S}>\Pi^{O}$ (so the partial network is not pairwise stable); and $\Pi^{C}>\Pi^{S}$ (so the star network is not pairwise stable). The final inequality also establishes, of course, that the complete network is pairwise stable.

However, the complete network is strongly stable only if $\beta$ is sufficiently small. There will be no coalitional deviation to either the star network (from the pairwise stability analysis above) or to the empty network (because $\Pi^{C}>\Pi^{E}$ ). A coalitional deviation to the partial network, where two of the firms in the complete network sever their links with the third, can be ruled out as long as $\Pi^{C}>\Pi^{I}$ - that is, as long as $\beta$ is sufficiently small (technically, $\beta<\beta^{* *}$ ).

Putting the last result slightly differently, a coordinated wage-setting system destabilises the complete network when spillovers are large - in much the same way, qualitatively, as occurs under centralisation. In this case, a coalition of two firms has incentives to sever its links with 
the third firm in order to form the partial network. This is so because when the spillover level is high enough, the competitive advantage of the linked firms in the partial network is large enough to outweigh the negative business stealing effect that stems from the lower wage costs of the isolated firm. ${ }^{19}$ Hence, the complete network emerges as the unique strongly stable network only when spillovers are not too large.

Therefore, to understand network formation under coordination, we might say that the same intuition applies as under decentralisation when spillovers are sufficiently small: that is, the complete network is strongly stable because $\Pi^{C}>\Pi^{I}$. However, the same intuition applies as under centralisation when spillovers are sufficiently large: that is, the strong stability of the complete network is undermined by $\Pi^{I}>\Pi^{C}$, which provokes a group deviation to the partial network. ${ }^{20}$

Within the "common" ranking of profits (3), the relative position of $\Pi^{I}$ under coordination is a halfway house - lower than under centralisation but higher than under decentralisation. ${ }^{21}$ This can be explained as follows. In the partial network under coordination, the linked (insider) firms face higher wages than the outsider, but the wage differential between the insiders and the outsider is lower than under decentralised wage-setting. Indeed, using the equilibrium expressions in Mauleon et al. and Appendix, the insider/outsider wage gap under decentralised and coordinated wage-setting is given by

$$
\begin{gathered}
w_{i}^{d}-w_{3}^{d}=\frac{4032(a-\bar{c}) \beta(10-3 \beta)}{1117225-9027 \beta(10-3 \beta)} \\
w_{i}^{c}-w_{3}^{c}=\frac{8(a-\bar{c})(2-\beta) \beta}{793-29(2-\beta) \beta}
\end{gathered}
$$

\footnotetext{
${ }^{19}$ Recall that, in contrast to centralisation, the wage is not uniform under coordination. Thus, coordination combines elements of the other two wage-setting systems: a centralised union but firm-specific wages.

${ }^{20}$ Note, however, that the partial network is not pairwise stable (and so cannot be strongly stable) under coordination because, unlike under centralisation with large $\beta, \Pi^{H}>\Pi^{I}$ and $\Pi^{S}>\Pi^{O}$ so there will be a pairwise deviation to the star network.

${ }^{21}$ Under coordination, the level of $\Pi^{I}$ relative to the other profit terms is either the same as under decentralisation or higher. Likewise, under centralisation, the relative level of $\Pi^{I}$ is either the same as under coordination or higher.
} 
where the superscripts $d$ and $c$ denote decentralisation and coordination, respectively, and $i=$ 1,2. It is straightforward to show that $w_{i}^{d}-w_{3}^{d}>w_{i}^{c}-w_{3}^{c} \forall \beta$. We note that this difference in the insider/outsider wage gap arises because, under coordination, the single industry-wide union internalises the negative externality created by a wage cut at a single firm - in a way that does not occur when three independent unions compete under decentralisation.

Compared to coordination, the larger insider/outsider wage gap within the partial network under decentralisation reduces the cost advantage of the linked firms relative to the isolated one, which works towards destabilising the partial network. Consequently, as we saw in Proposition 1 , the complete network is the unique strongly stable network when wages are set at the firmlevel by competing trade unions.

\section{Discussion}

In this section we investigate some additional aspects of our results.

Aggregate profits. We first examine the relation between unionisation structure and total profits. Setting aside extremely high values of within-network R\&D spillovers, we can show that total profits are increasing in the number of R\&D links within the industry for all three unionisation structures - that is, industry profits are maximised in the complete network. ${ }^{22}$ Therefore, recalling our equilibrium results on strongly stable networks, it is clear that individual and collective incentives for R\&D collaboration do not always coincide. Such misalignment is particularly severe under centralised wage-setting: the partial network is the unique strongly stable network, whereas it does not maximise industry profits. However, the conflict between individual and collective incentives is totally eliminated under a decentralised wage-setting system. Thus, in the pursuit of their private interests, industry participants are more likely to achieve an outcome that is collectively beneficial the less centralised the wage-setting system is.

\footnotetext{
${ }^{22}$ Relevant plots available on request.
} 
Aggregate effective R\&D investment and employment. Our analysis complements Haucap and Wey (2004), who investigate how the three different wage-setting regimes we have used affect firms' investment incentives and industry employment when two firms race to be the first to discover a new labour-saving innovation. They find - in line with us - that a decentralised system leads to the highest employment level. However, they also demonstrate that a centralised system creates the largest investment incentives. In contrast, we find that, for sufficiently large within-network R\&D spillovers, a decentralised union structure performs best in terms of equilibrium effective R\&D investment. ${ }^{23}$ Finally, in line with us, Haucap and Wey view coordination as the worst solution - in terms of both R\&D and employment performance. ${ }^{24}$ This is troubling because coordinated wage-setting arguably characterises recent trends in continental Europe towards greater wage flexibility.

Aggregate union utility. We now examine the relation between unionisation structure and total union utility. Under centralisation and coordination, we find that initially the complete, then the star, and eventually the partial network maximise total union utility; whereas, under decentralisation, only the complete and the star network are utility-maximising architectures. ${ }^{25}$ As it turns out, union and firm incentives for R\&D collaboration do not coincide. Importantly, however, the likelihood of a conflict becomes smaller as the degree of wage-setting centralisation decreases. ${ }^{26}$

It might also be wondered which unionisation leads to highest total union utility. Our analysis here - in line with the existing literature (e.g. Davidson, 1988) - reveals that a centralised system creates higher union utility than a decentralised one. ${ }^{27}$ This is because a centralised

\footnotetext{
${ }^{23}$ Again, relevant plots are available on request. As is usual (see, e.g., Kamien et al., 1992), "effective R\&D" refers to the total amount of $R \& D$ output that is applied to production - that is, the sum of a firm's own R\&D output and the R\&D outputs that it can access through links with other firms.

${ }^{24}$ We would therefore offer some support for Haucap and Wey's labour-market policy prescription: decentralisation (i.e. the banning of monopoly-unions altogether) is best. If, however, monopoly unions are allowed then wage negotiations should take place under non-discrimination rules - i.e. centralisation is preferred to coordination.

${ }^{25}$ Again, plots supporting these claims are available on request.

${ }^{26}$ Within the range of $\beta$ values, the likelihood of a conflict becomes approximately $60 \%, 43 \%$ and $6 \%$ in the move toward a less centralised wage-setting regime.

${ }^{27}$ This result, however, contrasts with Mukherjee and Pennings (2011), who demonstrate that total union utility can be higher under decentralised unions, as long as different firm characteristics (conditional on the unionisation
} 
union structure internalises the product-market effects of each firm's wage on the competitive position of its rivals. Interestingly, we also find that total union utility is higher under centralisation than under coordination - thus, centralisation is best in terms of union utility. One might suspect that an industry-wide union will always prefer coordination to centralisation since coordination gives extra 'degrees of freedom' to the union. However, this is not the case in the present setting: the effects of unionisation structure on union utility are influenced by the R\&D network and, as we have shown, centralisation and coordination induce the formation of different network structures.

Asymmetric labour productivities. As a caveat to the conclusions drawn above, we note that our analysis has assumed that labour productivity is equal across firms. We now consider the implications of relaxing this assumption. Bastos et al. (2009) provide a model where a central monopoly union sets a uniform wage for all workers in the industry. After a common wage floor has been determined, firm-specific rent-sharing takes place and results in a wage cushion on top of the wage floor. Their model also allows for (ex-ante) heterogeneous firms, as captured by a mean-preserving spread of labour productivities.

Embedding such a wage-setting system and firm heterogeneity within a network formation game with endogenous R\&D investments compromises analytical feasibility. However, the simple model employed here allows us to draw some conjectures about what would happen in this general setting. Specifically, more productive firms would form network links to strengthen their cost advantage relative to less productive ones. This would further increase firm heterogeneity, leading the central union to set a lower wage floor (so as to stimulate employment in the less productive firms). ${ }^{28}$ However, greater firm heterogeneity and a lower wage floor would also work toward a higher wage cushion (Bastos et al., 2009). If the extent of local rent-sharing is limited, then firms with linkages - who enjoy higher labour productivity than those without - would not structure) arise.

${ }^{28}$ Bastos et al. (2009, p. 443) note that this effect arises for "reasonable parameter configurations". 
suffer a lot in product-market competition. ${ }^{29}$ As a result, an asymmetric industry structure, such as a partial network, would emerge in equilibrium. If, however, local rent-sharing is substantial, then the attractiveness of the partial network may depend on the initial productivity spread between firms. That is, if the initial productivity differences are relatively small, the cost advantage of linked firms may be eroded by wage increases, thereby providing an incentive for denser networks.

Relation of our results to the wider literature. Our findings imply that denser R\&D networks are more likely to emerge as the degree of wage-setting centralisation decreases. This implied relationship between R\&D network formation and labour market deregulation is consistent with the stylised facts. However, other explanations have been advanced for understanding the growth in the number of $\mathrm{R} \& \mathrm{D}$ networks relative to more traditional forms of inter-firm cooperation. First, non-equity forms of partnerships, such as R\&D networks, offer participating firms increased flexibility to respond quickly to changing market conditions because they are typically easier to establish, administer and dissolve than equity-based agreements, such as RJVs (Narula and Hagedoorn, 1999). Such flexibility is particularly important in the modern business world as a result of short technology cycles and high costs of doing R\&D. Second, the legal framework across counties has undergone a process of harmonisation, which makes easier the enforcement of the contracts that underlie the organisation of $\mathrm{R} \& \mathrm{D}$ alliances. It is a task for future empirical work to attempt to discriminate between these various accounts of the increasing prevalence of $R \& D$ networks.

\section{Conclusion}

R\&D collaboration through networks in high-tech sectors has increased markedly over recent years. At the same time, many industrialised countries have reformed their wage-setting in-

\footnotetext{
${ }^{29}$ Rent-sharing can be seen as reflecting the relative bargaining powers of each firm and its local union under efficient bargaining.
} 
stitutions in the direction of greater decentralisation. Our model examines the influence of wage-setting institutions on $R \& D$ network formation, and our results are consistent with these two stylised facts.

A core idea is that a decentralised system of wage-setting, where labour is supplied to the industry through competing trade unions, creates a "business stealing effect": linked firms, who enjoy superior access to R\&D results, pay substantially higher wages than isolated firms, and this wage premium harms the networked firms in product-market competition. By bringing outsiders into the $\mathrm{R} \& \mathrm{D}$ network, which leads to the equalisation of wage rates across firms, the linked firms are able to reduce the business stealing effect. Hence, the complete R\&D network arises under decentralised wage-setting. In contrast, there is no business stealing effect under centralised wage-setting, where a single industy-wide union sets a uniform wage for all firms. In consequence, we show that the equilibrium network has an insider/outsider pattern under centralisation. Finally, under coordination, we show that the complete R\&D network arises in equilibrium, but only if within-network R\&D spillovers are sufficiently small.

Therefore, labour market deregulation towards more decentralised wage-setting structures is expected to induce the formation of denser $\mathrm{R} \& \mathrm{D}$ networks, and it can be seen as an alternative explanation for the empirical fact that $\mathrm{R} \& \mathrm{D}$ collaborations have become significantly more prevalent over recent years. Of course, a task for future work is a more thorough empirical testing of this hypothesis in the context of other potential explanations.

Our model has several special features, which further work might seek to relax. In particular, we have assumed a three-firm industry. As Goyal and Moraga-González (2001) note, the analysis of networks with an arbitrary number of firms is currently beyond reach. However, we can draw some conjectures about what one might expect to happen in that situation. We believe that the mechanisms that underlie our main result would still survive: in essence, a decrease in the degree of wage-setting centralisation widens wage differentials and favours firms with a small 
number of links relative to firms with a larger number of links, who will become more exposed to the hold-up problem. Thus, the progressive decentralisation of wage-setting is expected to induce a larger number of $R \& D$ collaborations.

A more thorough welfare analysis - bringing together consumer, producer and worker welfare into aggregate social welfare - is also a topic for future work.

\section{Appendix: Equilibrium outcomes}

Let $D=175+4 \beta(7 \beta-5) ; G=61-4 \beta(1-\beta) ; F=4900+\beta\left[22400-11853 \beta+98 \beta^{2}(37-12 \beta)\right]$;

$\Delta=3172+\beta\left[1128-433 \beta+6 \beta^{2}(15-4 \beta)\right] ; \Omega=175-9 \beta(10-7 \beta) ; H=793-29(2-\beta) \beta$.

The solutions for decentralised wage-setting come from MSMV (2008). In all cases, profit is given by $\pi_{i}=\left(p-c_{i}\right) q_{i}-\left(x_{i}\right)^{2}$. We use the superscripts $u$ (for uniform wage) and $c$ to denote centralisation and coordination respectively. We note that the linearity of our model ensures that second-order conditions are always satisfied. For the complete, star and partial networks, the equilibrium values are nonnegative for all values of $\beta, \beta \in(0,1]$.

\subsection{Complete network}

Equilibrium quantities in stage 4 are

$$
\begin{aligned}
q_{i}^{u} & =\frac{1}{4}\left[(a-\bar{c})-w+(3-2 \beta) x_{i}+(2 \beta-1)\left(x_{j}+x_{k}\right)\right] \\
q_{i}^{c} & =\frac{1}{4}\left[(a-\bar{c})-3 w_{i}+w_{j}+w_{k}+(3-2 \beta) x_{i}+(2 \beta-1)\left(x_{j}+x_{k}\right)\right]
\end{aligned}
$$

where the subscripts $i \neq j \neq k$ denote firms. 
In stage 3 , unions set wages

$$
\begin{aligned}
w^{u} & =\frac{1}{6}\left[3(a-\bar{c})+(1+2 \beta) \sum_{1}^{3} x_{i}\right] \\
w_{i}^{c} & =\frac{1}{2}\left[(a-\bar{c})+x_{i}+\beta\left(x_{j}+x_{k}\right)\right], \quad i \neq j \neq k .
\end{aligned}
$$

In stage 2, firms invest in R\&D to maximise their profits, $\pi_{i}=\left(q_{i}\right)^{2}-\left(x_{i}\right)^{2}$. Maximising profits and imposing symmetry $x_{i}=x_{j}=x_{k}$, we obtain the equilibrium firm-level R\&D investments

$$
\begin{aligned}
x^{u} & =(17-14 \beta)(a-\bar{c}) / D \\
x^{c} & =(3-2 \beta)(a-\bar{c}) / G .
\end{aligned}
$$

Substitutions yield the rest of the equilibrium solutions for the firm-level variables

$$
\left.\begin{array}{c}
q^{u}=24(a-\bar{c}) / D \\
\pi^{u}=7[41+4 \beta(17-7 \beta)](a-\bar{c})^{2} / D^{2} \\
w^{u}=96(a-\bar{c}) / D \\
q^{c}=8(a-\bar{c}) / G \\
\pi^{c}=(5+2 \beta)(11-2 \beta)(a-\bar{c})^{2} / G^{2} \\
w^{c}=32(a-\bar{c}) / G
\end{array}\right\} \text { Contralisation }
$$

\subsection{Star network}

Let firm 1 be the hub and firms 2 and 3 be the spokes. 
Under centralisation, the equilibrium values are

$$
\begin{aligned}
& x_{1}^{u}=(17-14 \beta)[28+9 \beta(16-7 \beta)](a-\bar{c}) / F \\
& x_{2}^{u}=x_{3}^{u}=2(34-21 \beta)[7+\beta(31-14 \beta)](a-\bar{c}) / F \\
& q_{1}^{u}=24[28+9 \beta(16-7 \beta)](a-\bar{c}) / F \\
& q_{2}^{u}=q_{3}^{u}=96[7+\beta(31-14 \beta)](a-\bar{c}) / F \\
& \pi_{1}^{u}=7(1+2 \beta)(41-14 \beta)[28+9 \beta(16-7 \beta)]^{2}(a-\bar{c})^{2} / F^{2} \\
& \pi_{2}^{u}=\pi_{3}^{u}=28(2+3 \beta)(82-21 \beta)[7+\beta(31-14 \beta)](a-\bar{c})^{2} / F^{2} \\
& w^{u}=244[12+\beta(56-25 \beta)](a-\bar{c}) / F
\end{aligned}
$$

Under coordination, the equilibrium values are

$$
\begin{aligned}
& x_{1}^{c}=(3-2 \beta)[52+3 \beta(8-3 \beta)](a-\bar{c}) / \Delta \\
& x_{2}^{c}=x_{3}^{c}=6(2-\beta)[13+\beta(5-2 \beta)](a-\bar{c}) / \Delta \\
& q_{1}^{c}=8[52+3 \beta(8-3 \beta)](a-\bar{c}) / \Delta \\
& q_{2}^{c}=q_{3}^{c}=32[13+\beta(5-2 \beta)](a-\bar{c}) / \Delta \\
& \pi_{1}^{c}=(11-2 \beta)(5+2 \beta)[52+3 \beta(8-3 \beta)]^{2}(a-\bar{c})^{2} / \Delta^{2} \\
& \pi_{2}^{c}=\pi_{3}^{c}=4(22-3 \beta)(10+3 \beta)[13+\beta(5-2 \beta)]^{2}(a-\bar{c})^{2} / \Delta^{2} \\
& w_{1}^{c}=16(104+\beta(44-17 \beta)) / \Delta \\
& w_{2}^{c}=w_{3}^{c}=8(208+3 \beta(28-11 \beta)) / \Delta
\end{aligned}
$$

\subsection{Partial network}

Let firms 1 and 2 be the linked insiders in the partial network and firm 3 be the isolated outsider. 
Under centralisation, the equilibrium values are

$$
\begin{aligned}
& x_{1}^{u}=x_{2}^{u}=(17-7 \beta)(a-\bar{c}) / \Omega \\
& x_{3}^{u}=17[7-\beta(10-7 \beta)](a-\bar{c}) / 7 \Omega \\
& q_{1}^{u}=q_{2}^{u}=24(a-\bar{c}) / \Omega \\
& q_{3}^{u}=24[7-\beta(10-7 \beta)](a-\bar{c}) / 7 \Omega \\
& \pi_{1}^{u}=\pi_{2}^{u}=7(1+\beta)(41-7 \beta)(a-\bar{c})^{2} / \Omega^{2} \\
& \pi_{3}^{u}=41[7-\beta(10-7 \beta)]^{2}(a-\bar{c})^{2} / 7 \Omega^{2} \\
& w^{u}=32[21-\beta(10-7 \beta)](a-\bar{c}) / 7 \Omega
\end{aligned}
$$

Under coordination, the equilibrium values are

$$
\begin{aligned}
& x_{1}^{c}=x_{2}^{c}=13(3-\beta)(a-\bar{c}) / H \\
& x_{3}^{c}=3[13-(2-\beta) \beta](a-\bar{c}) / H \\
& q_{1}^{c}=q_{2}^{c}=104(a-\bar{c}) / H \\
& q_{3}^{c}=8[13-(2-\beta) \beta](a-\bar{c}) / H \\
& \pi_{1}^{c}=\pi_{2}^{c}=169(11-\beta)(5+\beta)(a-\bar{c})^{2} / H^{2} \\
& \pi_{3}^{c}=55[13-(2-\beta) \beta]^{2}(a-\bar{c})^{2} / H^{2} \\
& w_{1}^{c}=w_{2}^{c}=8[52-(2-\beta) \beta](a-\bar{c}) / H \\
& w_{3}^{c}=16[26-(2-\beta) \beta](a-\bar{c}) / H
\end{aligned}
$$




\subsection{Empty network}

The symmetric equilibrium values are

$$
\left.\begin{array}{r}
x^{u}=\frac{17(a-\bar{c})}{175} \\
q^{u}=\frac{24(a-\bar{c})}{175} \\
\pi^{u}=\frac{41(a-\bar{c})^{2}}{4375} \\
w^{u}=\frac{96(a-\bar{c})}{175}
\end{array}\right\} \text { Centralisation }
$$

\section{References}

[1] Amir, R. (2000) "Modelling imperfectly appropriable R\&D via spillovers," International Journal of Industrial Organisation, 18, 1013-1032.

[2] d' Aspremont, C. and Jacquemin, A. (1988) "Cooperative and Noncooperative R\&D in Duopoly with Spillovers," American Economic Review, 78, 1133- 37.

[3] Bastos, P., Monteiro, N. and Straume O.R. (2009) "Firm heterogeneity and wages in unionised labour markets: Theory and evidence," Labour Economics, 16, 440-450.

[4] Calabuig, V. and González-Maestre, M. (2002) "Union structure and incentives for innovation," European Journal of Political Economy, 18,177-192.

[5] Davidson, C. (1988) "Multiunit bargaining in oligopolistic industries," Journal of Labour Economics, 6, 397-422. 
[6] Deroian, F. and Gannon, F. (2006) "Quality-improving alliances in differentiated oligopoly," International Journal of Industrial Organization, 24(3), 629-637.

[7] Grout, P.A. (1984) "Investment and wages in the absence of binding contracts: a Nash bargaining approach," Econometrica, 52, 449-460.

[8] Goyal, S. and Moraga-González, J.L. (2001) "R\&D Networks," Rand Journal of Economics, $32(4), 686-707$.

[9] Haucap, J. and Wey, C. (2004) "Unionisation structures and innovation incentives," Economic Journal, 114, 149-165.

[10] Jackson, M.O. and van den Nouweland, A. (2005) "Strongly Stable Networks," Games and Economic Behavior, 51(2), 420-444.

[11] Jackson, M.O. and Wolinsky, A. (1996) "A Strategic Model of Social and Economic Networks," Journal of Economic Theory, 71, 44-74.

[12] Kamien, M.I., Muller, E., and Zang, I. (1992) "Research Joint Ventures and R\&D Cartels," American Economic Review, 85, 1293-1306.

[13] Manasakis, C. and Petrakis, E. (2009) "Union structure and firms' incentives for cooperative R\&D investments", Canadian Journal of Economics, 42, 665-693.

[14] Mauleon, A., Sempere-Monerris, J.J., and Vannetelbosch, V. (2008) "Networks of Knowledge among Unionized Firms," Canadian Journal of Economics, 41, 971-997.

[15] Menezes-Filho, N., Ulph, D. and Van Reenen, J. (1998) "The Impact of Unions on R\&D: Empirical Evidence," European Economic Review, 42, 919-930.

[16] Mukherjee, A. and Pennings, E. (2011) "Unionization structure, licensing and innovation," International Journal of Industrial Organization, 29, 232-241. 
[17] Narula, R. and Duysters, G. (2004) "Globalisation and trends in international R\&D alliances," Journal of International Management, 10, 199-218.

[18] Narula, R. and Hagedoorn, J. (1999) "Innovating through strategic alliances: moving towards international partnerships and contractual agreements," Technovation, 19, 283-294.

[19] OECD (2004) "Employment Outlook," Paris: OECD.

[20] Poyago-Theotoky, J. (1995) "Equilibrium and Optimal Size of a RJV in an Oligopoly with Spillovers", Journal of Industrial Economics, 43(2): 209-226.

[21] Roijakkers, N. and Hagedoorn, J. (2006) "Inter-firm R\&D partnering in pharmaceutical biotechnology since 1975: Trends, patterns, and networks," Research Policy, 35, 431-446.

[22] Suzumura, K. (1992) "Cooperative and Noncooperative R\&D in an Oligopoly with Spillovers," American Economic Review, 82, 1307-1320.

[23] Tauman, Y. and Weiss, Y. (1987) "Labour unions and the adoption of new technology," Journal of Labour Economics, 5, 477-501.

[24] Ulph, A. and Ulph, D. (1994) "Labour markets and innovation: ex-post bargaining," European Economic Review, 38, 195-210.

[25] Ulph, A. and Ulph, D. (2001) "Strategic Innovation with Complete and Incomplete Labour Market Contracts," Scandinavian Journal of Economics, 103, 265-282.

[26] Zikos, V. (2010) "R\&D Collaboration Networks in Mixed Oligopoly", Southern Economic Journal, 77, 189-212.

[27] Zirulia, L. (2012) "The role of spillovers in R\&D network formation", Economics of Innovation and New Technology, 21(1), 83-105. 


\section{Appendix: For Referees - Not For Publication}

Figure 1: Firm-Level Profits under Centralised Wage-Setting ${ }^{30}$

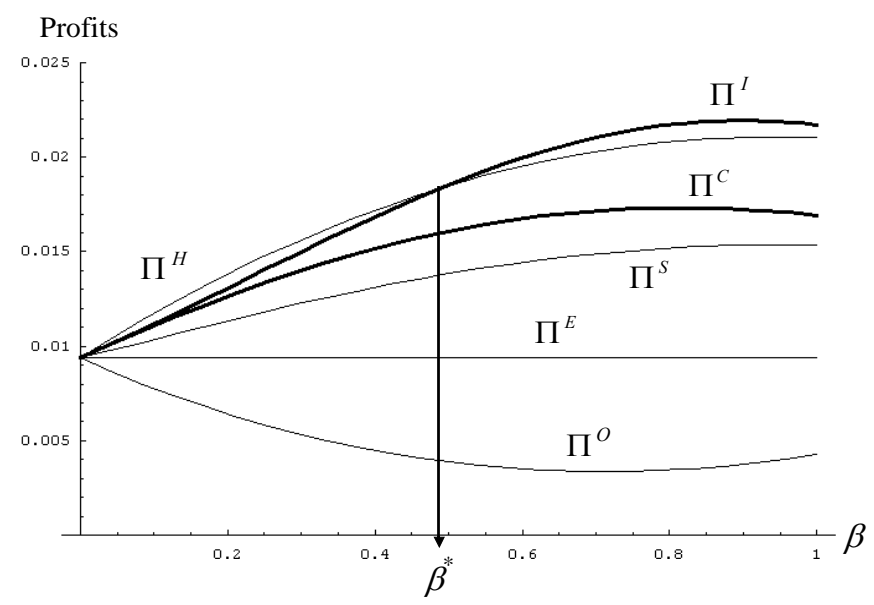

Key: $\Pi^{H}$ denotes the hub firm's profits in the star network; $\Pi^{I}$ denotes the profits of an insider (linked) firm in the partial network; $\Pi^{C}$ denotes a firm's profits in the complete network; $\Pi^{S}$ denotes a spoke firm's profits in the star network; $\Pi^{E}$ denotes a firm's profits in the empty network; and $\Pi^{O}$ denotes the profits of outsider (isolated) firm in the partial network.

Figure 2: Firm-Level Profits under Coordinated Wage-Setting

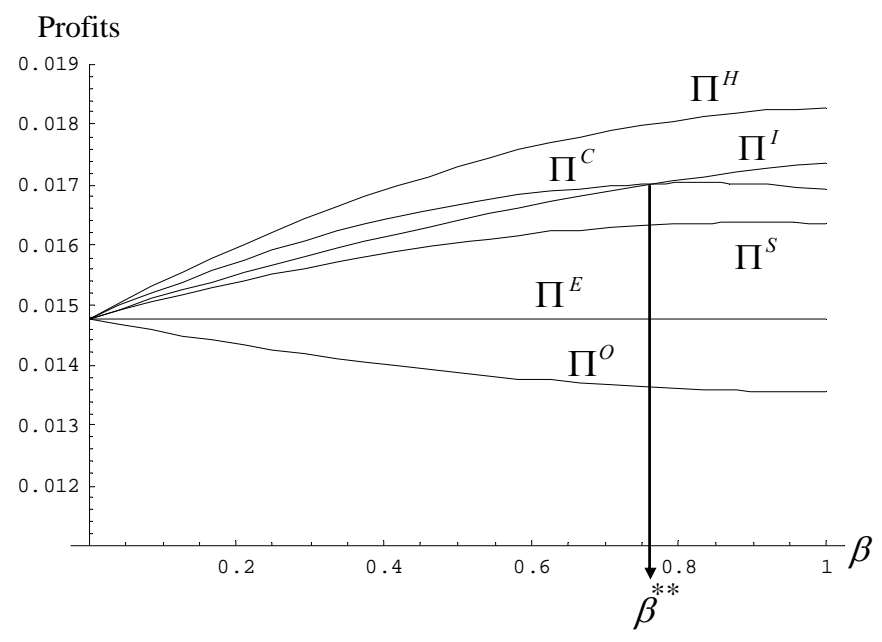

Key: As figure 1 above.

\footnotetext{
${ }^{30}$ We use "Mathematica 4" for the Figures. Since $a-\bar{c}$ is a scaling parameter, in all plots we have set it equal to 1 .
} 
Figure 3: Aggregate Profits under Centralised Wage-Setting

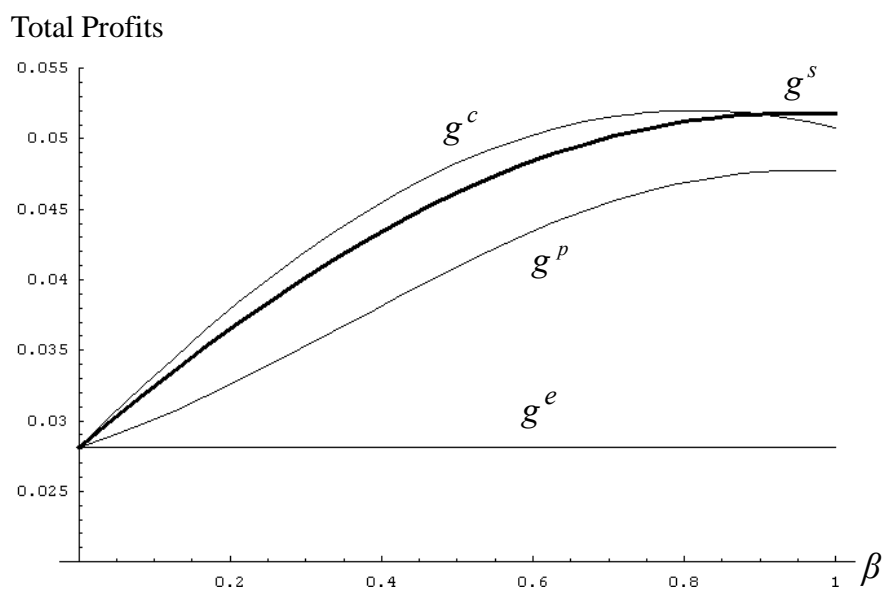

Key: $g^{c}$ denotes industry profits in the complete network; $g^{s}$ denotes industry profits in the star network; $g^{p}$ denotes industry profits in the partial network; and $g^{e}$ denotes industry profits in the empty network.

Figure 4: Aggregate Profits under Coordinated Wage-Setting

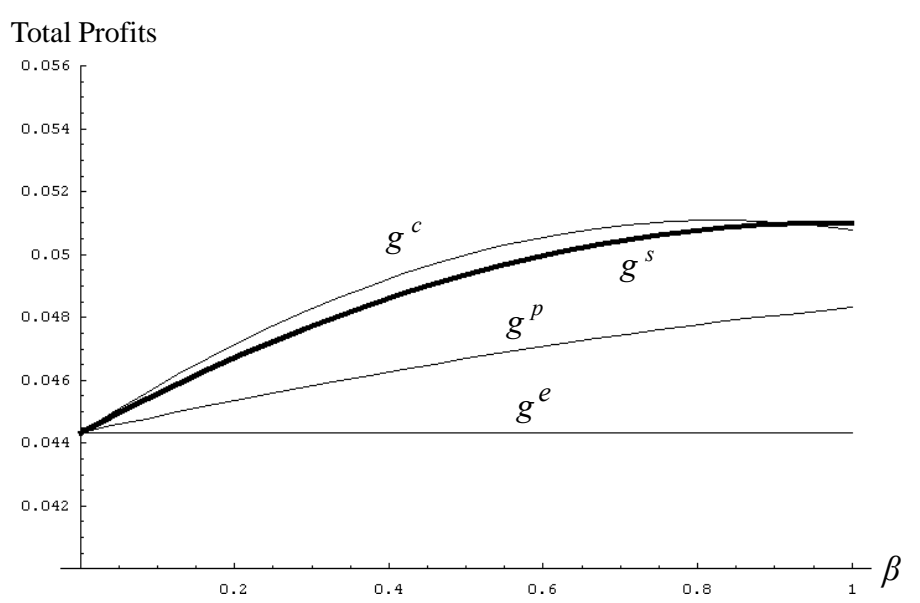

Key: As figure 3 above. 
Figure 5: Aggregate Effective R\&D Investment

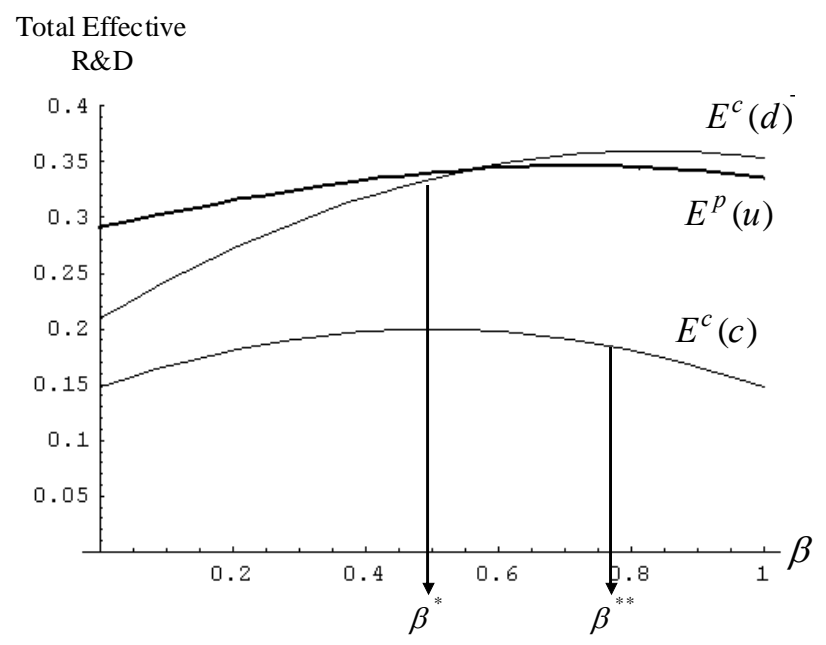

Key: $E^{c}(d)$ denotes aggregate effective $\mathrm{R} \& \mathrm{D}$ in the complete network under decentralised $(d)$ wage-setting; $E^{p}(u)$ denotes aggregate effective $\mathrm{R} \& \mathrm{D}$ in the partial network under centralised $(u)$ wage-setting; and $E^{c}(c)$ denotes aggregate effective $\mathrm{R} \& \mathrm{D}$ in the complete network under coordinated $(c)$ wage-setting.

Figure 6: Aggregate Employment

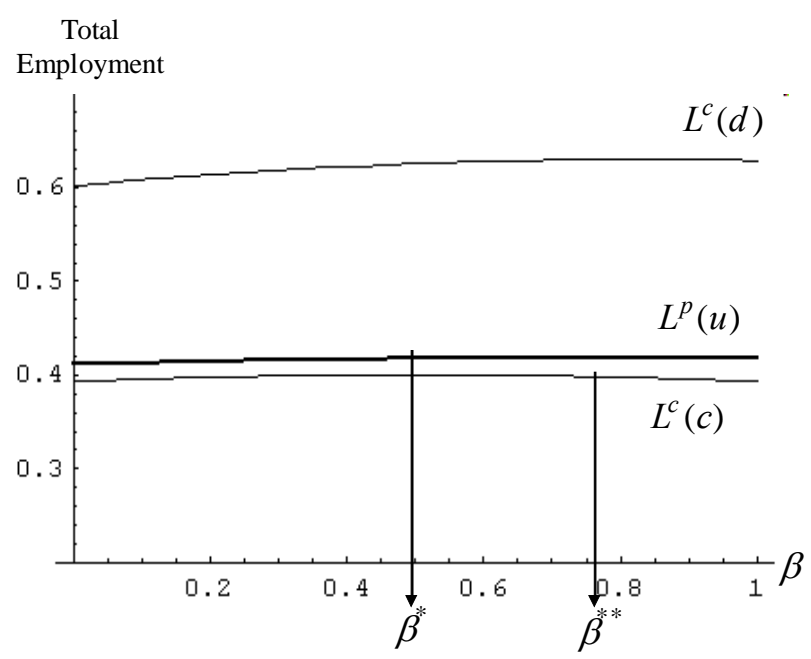

Key: $L^{c}(d)$ denotes industry employment in the complete network under decentralised $(d)$ wage-setting; $L^{p}(u)$ denotes industry employment in the partial network under centralised $(u)$ wage-setting; and $L^{c}(c)$ denotes industry employment in the complete network under coordinated $(c)$ wage-setting. 
Figure 7: Total Union Utility under Decentralised Wage-Setting

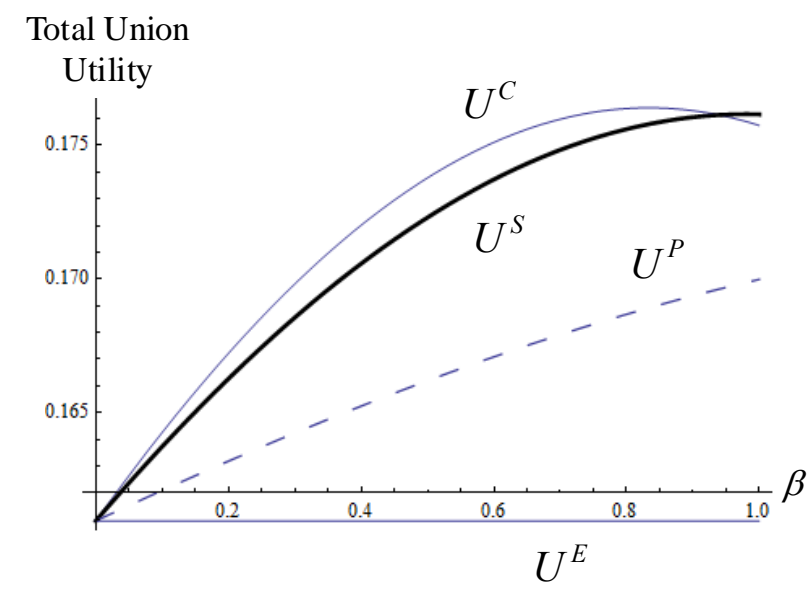

Key: $U^{C}$ denotes total union utility in the complete network; $U^{S}$ denotes total union utility in the star network; $U^{P}$ denotes total union utility in the partial network; and $U^{E}$ denotes total union utility in the empty network.

Figure 8: Total Union Utility under Centralised Wage-Setting

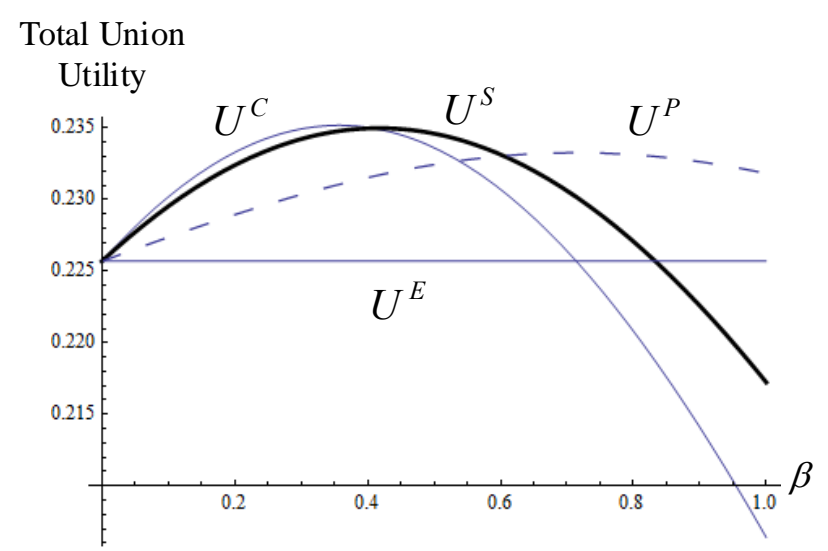

Key: As figure 7 above. 
Figure 9: Total Union Utility under Coordinated Wage-Setting

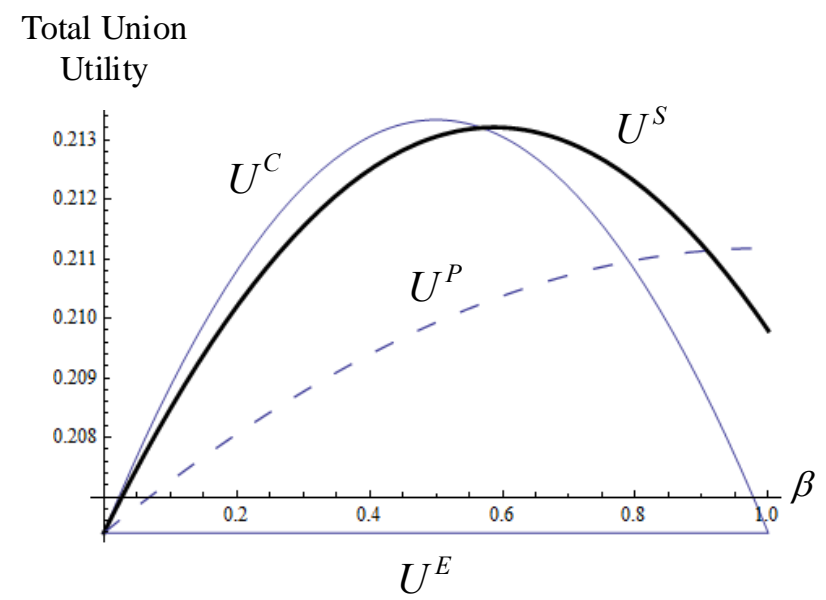

Key: As figure 7 above.

Figure 10: Total Union Utility - Comparison between Unionisation Structures

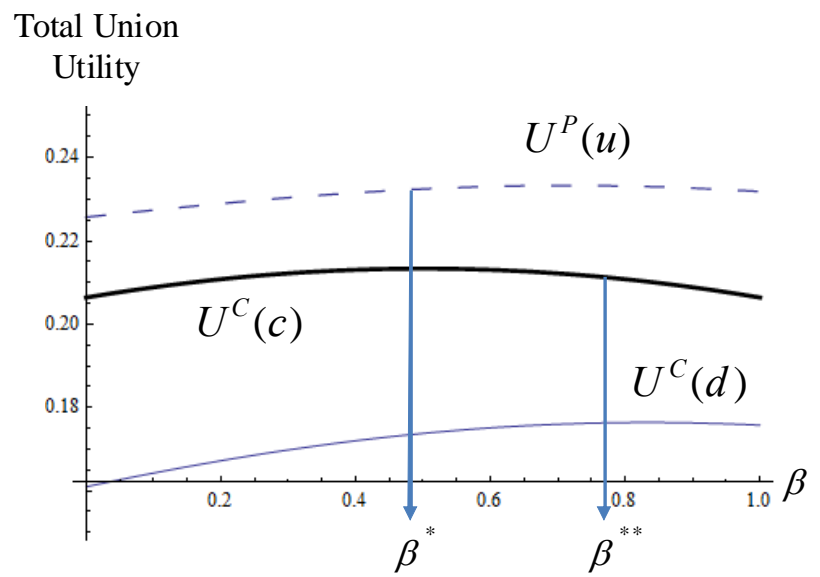

Key: $U^{C}(d)$ denotes total union utility in the complete network under decentralised $(d)$ wage-setting; $U^{P}(u)$ denotes total union utility in the partial network under centralised $(u)$ wage-setting; and $U^{C}(c)$ denotes total union utility in the complete network under coordinated $(c)$ wage-setting. 